\title{
Introdução - Cultura material no universo dos Impérios europeus modernos
}

José Newton Coelho Meneses ${ }^{1}$

Render-se ao óbvio

Os eventos da história podem significar para o pesquisador um encontro com as formas materiais que deles são parte. Essas podem, para quem thes é sensível, funcionar como um choque sensorial. ${ }^{2}$ Nessa agressão aos sentidos do investigador pode fundamentar-se a força da leitura dos artefatos de modo a compreendê-los. Dependendo da sensibilidade do pesquisador le de suas escolhas) a compreensão dessas estruturas materiais leva-o a vê-las como coisas do homem e, mais ainda, partes do humano. Às vezes, as percebe como componentes indistintos das opções do homem, de suas ações, de seus atos, enfim, dos fatos históricos. Os fatos do homem social incorporam indivisivelmente seus artefatos.

Pensar sobre os elementos materiais da cultura e tê-los como fonte de compreensão do mundo dos homens é o que fazem os autores que apresentam interpretações do mundo neste dossiê. Mundo de vários tempos; temporalidades que buscam uma certa unidade desigual. Embora marcadas, pelos organizadores do dossiê, como "o universo dos impérios europeus modernos", são complexas e díspares as temporalidades próprias deste universo. Os tempos marcam os objetos tanto quanto os objetos marcam o tempo. Os elementos materiais dos "impérios europeus modernos" têm a diversidade dos mesmos impérios na modernidade. Vastos impérios! Tempos diversos! Artefatos amplos!

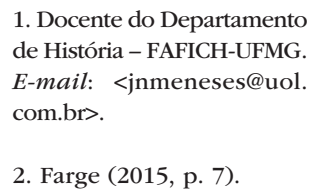

1. Docente do Departamento de História - FAFICH-UFMG. E-mail: <jnmeneses@uol. com.br>.

2. Farge (2015, p. 7) 
3. Rede (2012), Appadurai (1986).

4. Miller (1987, 1998, 2013).
Sacros, de consumo, simbólicos, significativos e de técnicas, não importa, são as coisas materiais dos gestos do homem.

Os objetos dão-nos a compreensão de nós e dos outros. Identificam culturas e nos evidenciam a "marcha do tempo". Do tempo dos homens. Do homem no tempo.

Alguns diagnosticam os objetos como a parte "não humana" da vida. Ora, é preciso desumanizar a vivência humana para perceber o material como humano e ver a vida social como a indivisibilidade entre o humano e o material. Em exercício de contraponto é necessário humanizar o artefato. $\bigcirc$ conjunto de objetos de uma vivência, a chamada "cultura material", é mais que o trabalho do homem, o seu produto, o consumo do homem, a técnica e a tecnologia que ele cria, o saber que ele inventa, o progresso da sociedade humana, a simbologia ou a filosofia do homem. $\bigcirc$ objeto é o homem; é a extensão do seu gesto. É o próprio gesto.

gesto é artifício, é expressão, é movimento corporal que une o corpo e a materialidade própria do organismo humano. $\bigcirc$ artefato, materialidade que estende o gesto ao seu mundo, é instrumento das intenções, opções e sentimentos do homem.

Como lê o objeto o historiador, o antropólogo, o sociólogo, o filósofo? Como reflexo, representação, apropriação? Deveria lê-lo como indistinguível do humano! $\bigcirc$ artefato é legível como mercadoria, consumo, convivialidade, celebração, urbanidade, ruralidade, produto, trabalho? Os textos que se seguem respondem a esses questionamentos e levantam questões novas para se pensar 0 homem social e a cultura material que ele constrói.

A "cultura material" indefinida e indefinível não existe mais para o cientista social. Ela tornou-se definível com claridade ao conjugar-se com a dinâmica do homem social e com as leituras das várias disciplinas sociais. ${ }^{3}$ Teorias e perspectivas distintas têm contribuído para enriquecer as análises da materialidade das vivências históricas, a despeito de ser comum, ainda, lermos e ouvirmos discursos que clamam por maiores definições do que seja "cultura material" e por metodologias que permitam seu uso como fonte de compreensão da história dos homens.

Há, entretanto, uma dinâmica tradição nas ciências humanas em tomar o campo da cultura material para se compreender as vivências históricas. Essa dinâmica, como é próprio às tradições, se apresenta em ritmos de manutenção de perspectivas e de questionamentos a formas de análises e de leitura dos artefatos. Uma nova antropologia do consumo, por exemplo, crítica à perspectiva semiótica - que trata a materialidade como algo inanimado ou simples instrumento da representação social - impõe ao objeto a condição de constituinte do homem. ${ }^{4}$ Aí o artefato material é gerador de sentidos para a compreensão das sociedades, não apenas para a representação delas. $\bigcirc$ simbólico e o material são, assim, analisados como unidade.

Para Daniel Miller, os trecos materiais "têm uma capacidade notável de se desvanecer diante de nossos olhos, tornam-se naturalizados, aceitos como 
pontos pacíficos, cenário ou moldura de nossos comportamentos." 5 A solução para Miller seria, então, colocar nossas abstrações teóricas "de volta na algazarra da vida cotidiana e na gloriosa confusão de contradição e ambivalência que ali se encontram". 6

De modo geral, a historiografia, com honrosas exceções que não enumeraremos aqui para não cometermos injustiças, costuma dar um tratamento analítico restrito à chamada "cultura material", tratando-a como reflexo da construção social e não como um repertório de manifestações e de elementos da cultura integrados em sua constituição histórica. Assim, os artefatos, os objetos, as materialidades são vistos como produtos, como consumos, como instrumentos técnicos do homem em sociedade, quando deveriam ser analisados como documentos do viver, das experiências de vida.

Não se deve ler os objetos deslocados do seu uso, dos seus sentidos sociais. Um garfo, por exemplo, tem sentido tanto como instrumento, quanto gesto humano; tanto como artefato, quanto fato. Um garfo é detentor de sentidos sociais. garfo é um fato sócio-histórico.

A despeito da crítica acima, é grande a contribuição dos estudos de cultura material na área de história. Como vem acontecendo em sua tradição, ela possibilita aos historiadores compreender dimensões importantes da sociedade ao aquilatar a produção de riquezas, as construções técnicas e tecnológicas, as especificidades de categorias sociais, as distinções de ritos da vida, as representações sociais e simbólicas etc. Contribuição maior esses estudos dão quando dimensionam junto com tudo isso as experiências humanas, as vivências. Os objetos, afinal, são parte do conjunto complexo e dinâmico do viver.

De tão presentes, comuns, banais ${ }^{7}$ e importantes para a vida, tendemos a naturalizar os objetos, desumanizá-los. Esquecemos que são construções do homem; são cultura. Repetimos a forma dicotômica de tratar o humano opondo as tríades mente/pensamento/linguagem à corpo/prática/matéria. Ao naturalizar os artefatos determinamos a eles a condição de obviedade de clareza axiomática, evidência intuitiva. É preciso valorizar o que parece óbvio; pensar as obviedades com curiosidade cognitiva. Necessário, enfim, deixar de opor o material ao simbólico, como temos deixado de opor o natural ao cultural.

Os textos que aqui se apresentam rendem-se à riqueza do que é óbvio. Eles impõem aos artefatos da vida a historicidade da qual são parte.
5. Miller (2013, p. 228).

6. Miller (2013, p. 230).

7. Roche (2000), Garcia (2011). 


\section{REFERÊNCIAS}

APPADURAI, Arjun. (org.). The social life of things. Cambbridge: Cambridge University Press, 1986.

FARGE, Arlette. Le peuple et les choses. Paris au XVIIIe siècle. Montrouge: Bayard, 2015.

GARCIA, Tristan. Forme et objet. Un traité des choses. Paris: PUF, 2011.

MILLER, Daniel. Material culture and mass consumption. Oxford: Blackwell, 1987.

MILLER, Daniel. (org.) Material cultures: Why some things matter. Chicago: The University of Chicago Press, 1998.

MILLER, Daniel. Trecos, Troços e Coisas. Estudos antropológicos sobre a cultura material. Rio de Janeiro: Zahar, 2013.

REDE, Marcelo. História e cultura material. In: CARDOSO, Ciro F.; VAINFAS, Ronaldo. (orgs.). Novos domínios da História. Rio de Janeiro: Campus/ELSEVIER, 2012, p. 133-150.

ROCHE, Daniel. História das coisas banais. Nascimento do consumo. Séc. XVII-XIX. Rio de Janeiro: Rocco, 2000.

Artigo apresentado em 06/04/2017. Aprovado em 15/04/2017. 